\title{
Gender-Specific Reactions to Environmental Hazards in the Netherlands
}

\author{
Jan M. Gutteling ${ }^{1}$ and Oene Wiegman
}

University of Twente

In this study differences in appraisal, feelings of insecurity, and ways of coping were assessed between men and women, and related to their level of formal education. The sample consisted of 513 men and women who responded to a mailed questionnaire dealing with the hazards of living in an estate with soil pollution, near a chemical plant, or in the vicinity of a planned site for the storage of radioactive waste. The results show that women assess the hazards as more unacceptable and threatening, and report more feelings of insecurity than men. A number of possible explanations is reviewed.

Hazards are inherent to industrial and technological developments. In this study these hazards are termed "environmental hazards," including all hazards originating from the application of industry and technology which would have consequences for the environment or for human health. Research into people's reactions to such hazards has been conducted, for example, among people living in the vicinity of hazardous installations, such as nuclear power stations (Baum, Gatchel, \& Shaeffer, 1983; Ester, Mindell, Van der Linden, \& Van der Pligt, 1983) and chemical plants (Gutteling, Wiegman, \& Boer, 1990; Stallen \& Tomas, 1988; Wiegman, Gutteling, \& Boer, 1990, 1991; Wiegman, Komilis, Cadet, Boer, \& Gutteling, 1992) and among people living in estates with soil pollution (Baas, De Boer, Geerlings, Hoefnagel, \& Van der Wouden, 1985). The

\footnotetext{
${ }^{1}$ To whom correspondence should be addressed at Department of Psychology, University of Twente, P.O. Box 217, 7500 AE Enschede, the Netherlands.
} 
conclusion common to these studies is that worry and feelings of insecurity with respect to these hazards are present throughout the population, but their intensity differs. Pilisuk and Acredolo (1988) stated that "there exists a general fear of technological dangers, and this general concern is strongest among those who are least part of the benefits of the technological order, i.e. the poor, women, minorities, and the less educated" (p. 19). The assumption of these authors is that, on the basis of a number of demographic variables, groups can be distinguished that differ in feelings of insecurity. In general, not much research has been conducted to investigate the relation between demographic characteristics and reactions to environmental hazards. However, it has been found quite consistently that women react differently to environmental hazards than men (Pilisuk \& Acredolo, 1988; Stallen \& Tomas, 1988; Vlek \& Stallen, 1979). A number of explanations have been suggested, some of which are in accordance with explanations for gender-specific reactions or behaviors that are reported in other societal domains. Mostly, the explanatory mechanisms are relatively close to the observed gender specificity, and assume that gender differences either exist because they are expected (role differentiation), or because they are based on free choice or because circumstances do not allow other possibilities (see Diederen, 1989). For instance, an explanation that takes circumstances into account and aims specifically at feelings of fear was presented by Van der Ploeg, Defares, and Spielberger (1980), who suggested that women tend by nature to become afraid in a threatening situation more quickly than men. However, this last assumption is based on insufficient empirical support. Explanations based on free choice are also not applicable to gender differences in environmental hazards, because as research has shown these hazards are characterized mainly by their involuntariness and uncontrollability (Slovic, 1987; Fischer et al., 1991). Alternatively, Stallen and Tomas (1988) assumed that women are less oriented toward the economic importance of technology than men, and instead place more importance on the possible effects of environmental hazards on personal well-being and health. An alternative explanation, based on cultural differences between the sexes, is that women in general are less familiar with technology (Weenig, 1983). Differences in reactions between women and men have also been found for other hazard-related topics, such as criminality and health. Garofalo (1979) and Van den Bogaard (1990) found that women showed a greater fear of criminal victimization than men. Seydel (1989) found that women judged cancer to be more threatening than men. Garofalo (1979) assumes a role differentiation based on a socialization process in which typical females take a more dependent role. This dependency can be created by the woman showing a greater fear of criminality, which would render her 
more dependent on male protection. A similar explanation could also apply for hazards related to the environment or to health. We would like to emphasize that this explanation does not imply that women have more feelings of fear than men, but that they are less inhibited showing these feelings openly.

Gender is related to formal education. In general, in the Netherlands, women are less well educated than men. Formal education can be of importance for the reaction to environmental hazards, too, because these hazards are very complex and difficult to understand, and reacting to them may very well be based on the subjects' level of formal education. At present, little is known about the relation between formal education and reactions to environmental hazards. In some studies, it has been shown that people with less education have a relatively positive attitude toward the use of nuclear power (Renn, 1981). However, in a study in the Netherlands the opposite emerged: those with a higher level of education had a more positive attitude toward the use of nuclear power (Midden, 1986). In another recent study in the United States, Pilisuk and Acredolo (1988) again found a greater anxiety regarding the dangers of technology among people with a lower level of education. Also for other topics with which hazards are associated, it has been found that people with less education have more feelings of anxiety. For cancer, Gutteling, Seydel, and Wiegman (1986) and Seydel (1989) showed that those with less education judged cancer to be more threatening. Garofalo (1979) reported a similar result with respect to criminality. For all these topics, the individual is confronted with complex information, including a number of threatening aspects. Furthermore, the concept of probability is central to this information, and in general, the chance that the individual himself will be confronted with the hazard is quite small. Our assumption is that people with less education are less apt at cognitively processing the information on these minute probabilities and consequently place more emphasis on the threatening aspects of the information, which causes them to feel more threatened.

From the above can be derived that insight into the relation between gender and formal education and reactions to environmental hazards is rather fragmentary, which to a great extent is caused by the fact that most studies have concentrated on one particular type of hazard. The aim of this study is to determine the role of gender and formal education in reacting to three environmental hazards, namely the hazards associated with living in the vicinity of a chemical complex, the hazards associated with living in a soil-polluted estate, and the hazards associated with living in the vicinity of a planned above-ground storage facility for radioactive waste. 


\title{
PROCEDURE
}

The study was aimed at a cross section of the Dutch population. A random sample (1458 addresses) was chosen from the Post Office address data bank for private telephone owners. (People in our sample were not asked about ethnicity. In our country about 3 or $4 \%$ of the inhabitants are representatives of minority groups. On a proportional basis our sample should also contain about 3 or $4 \%$ of representatives of minorities. No ethnic data are available about the population in the Post Office address data bank.) In May 1985, the sample was sent a questionnaire. Both men and women took part in the study; half of the questionnaires included a letter addressed to a male addressee and the other half a letter addressed to a female. In the questionnaire the respondents were confronted with the following instruction:
Imagine the following situation:
you live in the vicinity of a large chemical plant where among other things plastics and artificial fertilizers are made. During the production process chemicals are used which could be dangerous for the environment.

After the respondent has answered a number of questions related to the above, (s)he is confronted with another hazard. The respondent then received the following instruction:

\author{
Imagine the following situation: \\ it has been established that the soil in \\ the estate you live in is seriously polluted.
}

After the respondent has answered similar questions relating to the latter hazard, he or she is confronted with one last hazard. The respondent received the following instruction:

\footnotetext{
Imagine the following situation: you live very close to an industrial site where in the near future an above-ground storage facility for radioactive waste will be built.
}

The three risk objects in the following are designated respectively as the "chemical plant," the "polluted estate," and "radioactive waste." As a manipulation check, the respondents were asked whether a location existed, within a radius of a few kilometers from their homes, which fitted the description of either the chemical plant, the polluted estate or the aboveground radioactive waste storage facility. (It is important to note here that 
at the time this research was being carried out, a governmental committee, which had been appointed the task of selecting locations for the aboveground storage of radioactive waste, was quite frequently on the news. The definitive choice of the location was at that time not yet known.)

\section{Dependent Variables}

The questionnaire assessed the cognitive, affective and behavioral reactions to the hazards. These were operationalized as follows:

The (Un)acceptability of the Environmental Hazards. These were expressed on a 5-point scale, on which the respondents indicated to what extent they objected to living in the vicinity of the hazard, and how unacceptable and risky they considered it to live near to such a hazard. The three items formed a very reliable scale (Cronbach's $\alpha=.90$ ). (A scale with an $\alpha$ between .60 and .69 is considered sufficiently reliable. A scale with an $\alpha$ between .70 and .79 is reliable, and with an $\alpha$ of .80 or higher is considered very reliable.)

The Threat Posed by the Environmental Hazards. On a 5-point scale the respondents indicated how threatened they felt by the possibility of an accident, to what extent they felt the consequences of such an accident could be kept under control and to what extent accidents could be prevented on the basis of safety regulations. The three items formed a reliable scale $(\alpha=.75)$.

"Unknown risk." Using a 5-point scale, the respondents indicated whether they were clearly aware of the consequences of an accident that could pose a threat to the surrounding area, whether a clear picture of the hazards involved had been presented on the television and the radio, and whether the experts had a clear knowledge of the hazards involved. The reliability of the scale formed by the three items, was sufficient $(\alpha=.62)$.

The Feelings of Insecurity. The respondents indicated on a 4-point scale to what extent they thought of the environmental hazards made them feel tense, nervous, restless/anxious, or afraid. The four items formed a very reliable scale $(\alpha=.92)$.

Coping with the Hazards. Here we distinguished between information seeking, the need for information, social interaction, avoiding the hazard, and intention to protest behavior. All these ways of coping with the hazard were measured on 5-point scales.

Information seeking was determined by asking the respondents to indicate to what extent they would consult 11 possible sources of information, such as the mass media, government organizations, or pressure groups, in 
order to obtain more information about that particular hazard. The 11 items formed a very reliable scale $(\alpha=.88)$.

The need for information was determined on the basis of questions such as "I would definitely watch television programmes dealing with that particular hazard," "I want to know for sure whether the information I have on that hazard is correct," "I will go and talk to other people in the same situation as myself." The items formed a very reliable scale $(\alpha=.81)$.

Social interaction was assessed by asking the respondents to indicate to what extent they would talk about the hazards to other members of the family, to neighbors, friends, acquaintances, or at work. The scale social interaction was very reliable $(\alpha=.81)$.

Avoidance was determined by the respondents indicating to what extent they tended to not get upset about the hazard, to act as if nothing was wrong, to accept the situation, and to try to think about something else. The four items formed a reliable scale $(\alpha=.77)$.

Intention to protest behavior was determined by questions relating to whether the respondents would take part in some form of protest activity, join a pressure group, call in the press, or talk to the local council. The four items formed a very reliable scale $(\alpha=.80)$.

\section{Other Variables}

The questionnaire also comprised questions to determine the respondents, gender, educational level, political and religious preference, and size of municipality and county and assessed their interest in environmental news in papers and on television, their trust in science and technology, and the nuisance they were currently experiencing from existing environmental problems.

\section{RESULTS}

In total, 588 subjects responded to the questionnaire (response approximately $40 \%$ ). Incompletely filled forms were not included in the analysis, so the number of respondents decreased to 513 , of which $35 \%$ were women. As manipulation check, the respondents were asked to indicate whether locations as described in the questionnaire existed within a distance of a few kilometers of their homes. Some $10 \%$ of the respondents indicated that this was the case for the risk objects chemical plant and polluted estate, and $2 \%$ for the risk object radioactive waste. 
In order to determine whether the respondents who took part in the survey formed a reliable cross section of the Dutch population, the respondents were compared for gender, political preference, religion, and size of municipality and county with demographic statistical figures of the Dutch population as a whole (CBS, 1985). No differences were found between the sample and the Dutch population as a whole for the variables religion $\left[\chi^{2}(4, N=513)=.94, \mathrm{~ns}\right]$, the size of the municipality in which the respondents lived $\left[\chi^{2}(5, N=513)=2.2\right.$, ns], the county in which the respondents lived $\left[\chi^{2}(4, N=513)=.43\right.$, ns] or political preference $\left[\chi^{2}(7, N=513)=2.23\right.$, ns]. An overrepresentation of men existed $\left[\chi^{2}(1, N=513)=4.6, p<.05\right]$. With the exception of gender, the sample represented a good cross section of the Dutch population as a whole.

No significant differences in interest in environmental news in the mass media existed between men and women $[F(1,398)=2.57$, ns $]$ or between people with a low average, or high level of education $[F(2$, $398)=1.99$, ns]. Furthermore, no significant differences were found for experienced nuisance from existing industrial or technological sources between men and women $[F(1,412)=2.48$, ns]. In general, people with an average or high level of education were experiencing slightly more nuisance than those with a low level of education $[F(2,412)=3.34, p<.05]$. The interaction between gender and level of formal education was not significant for interest in environmental news in the mass media or nuisance. Women were found to have more trust in science and technology than men $[F(1,412)=4.92, \mathrm{~ns}]$, while no difference was found for the various groups based on educational level. The interaction between gender and educational level for trust in science and technology is significant $[F(2$, $412)=4.70, p<.05]$, which indicates that women with an average $[F(1$, $205)=9.21, p<.01]$ or high level of education $[F(1,112)=3.42$, $p<.10$ ] have more trust in science and technology than men with comparable levels of education. Men and women with a low level of education do not differ in trust in science and technology $[F(1,134)=.99$, ns $]$.

\section{Gender Specific Reactions to Environmental Hazards}

Table I shows the average scores, $F$ values, and significance levels of a number of analyses of variance that were performed to assess the reactions to three environmental hazards of men and women and people that have a low, average, or high level of education. The dependent variables are the assessment of the hazards (i.e., unacceptability, threat, and unknown risk), feelings of insecurity, and the ways of coping with the hazard 
(i.e., social interaction, information seeking, protest behavior, avoidance, and need for information). As we have seen before, some $12 \%$ of the respondents indicated that one or more of the specific risk objects existed within a few kilometers of their homes. This could be of importance to their assessment of the risk. For that reason we used this factor as a covariate in our analyses. (It should be noted here that in consequent analyses without this factor as a covariate we did not find another pattern of significant or nonsignificant results.)

Table I shows that women compared to men assess all risk objects to be more threatening [chemical plant $F(1,452)=4.34, p<.05$; polluted estate $F(1,452)=4.06, p<.05$; radioactive waste $F(1,446)=10.14$, $p<.01]$. Furthermore, women rated all risk objects as more unacceptable [chemical plant $F(1,452)=4.86, p<.05$; polluted estate $F(1,452)=4.37$, $p<.05$; radioactive waste $F(1,446)=13.89, p<.001$ ]. With respect to the variable unknown risk, men and women differ regarding the risk object of radioactive waste $[F(1,446)=4.38, p<.05]$. Women assess this risk object as more unknown than men.

Men and women differ consistently with respect to the feelings of insecurity caused by the three risk objects. Women show more feelings of insecurity than men [chemical plant $F(1,436)=14.13, p<.001$; polluted estate $F(1,429)=15.86, p<.001$; radioactive waste $F(1,428)=15.25$, $p<.001]$.

Regarding the risk objects of chemical plant and polluted estate, men and women differ in their intention to seek information and their need for information. Women have a greater intention to seek information [chemical plant $F(1,421)=6.67, p<.01$; polluted estate $F(1,425)=7.94, p<.01$ ] and have more need for information than men [chemical plant $F(1$, $421)=5.88, p<.05$; polluted estate $F(1,425)=8.09, p<.01]$. No differences between men and women were found with respect to the other ways of coping with these two hazards, i.e., social interaction, intention to protest behavior, and avoidance. With respect to the risk object of radioactive waste, no significant differences in coping reactions were found between men and women.

\section{Formal Education Specific Reactions to Environmental Hazards}

The subjects were divided into three categories on the basis of their level of formal education, namely low, average, and higher. Table I also shows the results for the analyses of variance with level of formal education as factor. 
People with a lower level of formal education judge the risk object of radioactive waste as more unacceptable than people with higher levels of education $[F(2,446)=7.60, p<.001]$. On this question the other two risk objects do not show differences for educational groups. People with a higher level of education judge the risk object of polluted estate as more threatening than people with a lower level of education $[F(2,452)=3.91$, $p<.05]$ and the other two risk objects do not show differences for educational level. People with a lower or average level of education judge the risk objects of chemical plant $[F(2,452)=6.35, p<.01]$ and polluted estate $[F(2,452)=5.68, p<.01]$ to be less unknown than higher educated people.

From Table I can be derived that people with different levels of education do differ with respect to feelings of insecurity caused by the risk objects of chemical complex $[F(2,436)=3.11, p<.05]$ and polluted estate $[F(2,429)=4.32, p<.05]$. People with a lower level of education report more feelings of insecurity regarding these risk objects than people with higher levels of education. No difference between the educational groups in feelings of insecurity exists for the risk object of radioactive waste.

With respect to the ways of coping with the hazard, only differences were found between the educational groups with respect to information seeking regarding the risk objects of chemical complex $[F(2,421)=2.93$, $p=.05]$ and polluted estate $[F(2,425)=3.23, p<.05]$. People with an average level of education are less inclined to seek information than both people with a lower or a higher level of education. No differences between the educational groups were found for information seeking regarding the risk object of radioactive waste or for any of the other coping reactions (social interaction, intention to protest behavior, avoidance, or need for information) with respect to each of the risk objects.

\section{Interaction Effects Between Gender and Level of Education}

Table $I$ indicates that a number of significant interaction effects between gender and level of education were found. Regarding the risk object of chemical plant the interaction for perceived threat $[F(2,452)=3.97$, $p<.05]$ and for unknown risk $[F(2,425)=4.76, p<.01]$ are significant. Secondary analyses showed that women with an average level of education $[F(1,205)=6.82, p<.05]$ or with a higher level of education $[F(1$, $113)=3.92, p=.05$ ] assess this risk object as more threatening than men. For people with a lower level of education there exists no significant difference in perceived threat of the risk object of chemical complex $[F(1$, 


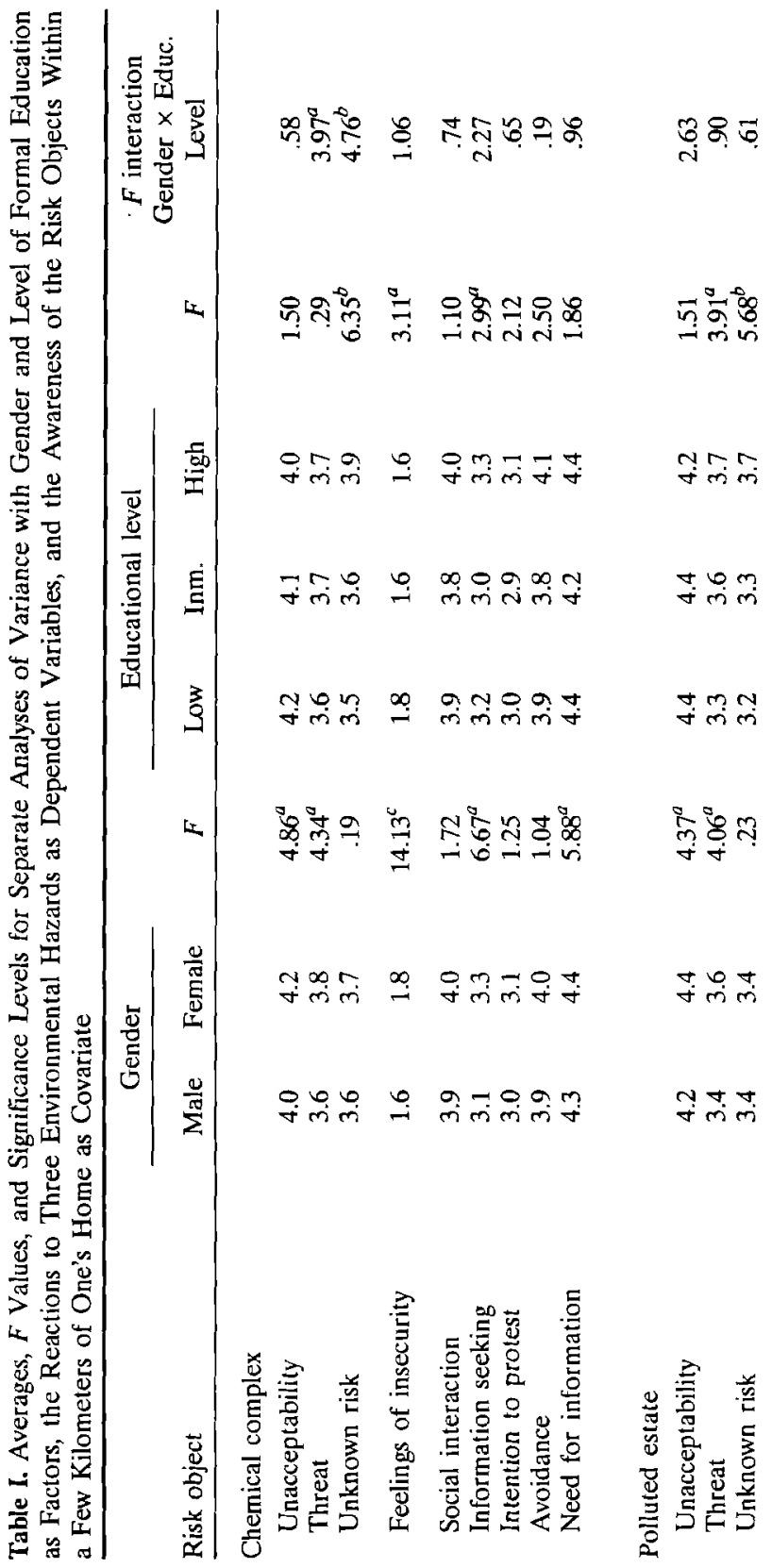




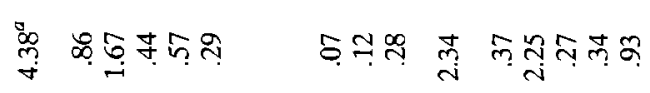

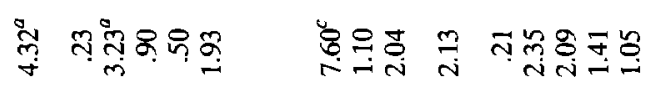

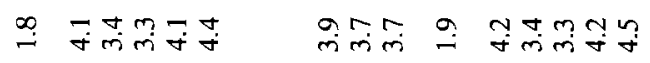

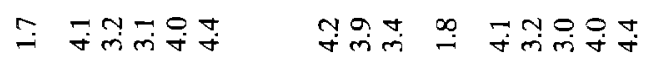

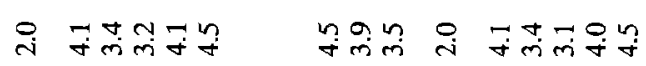

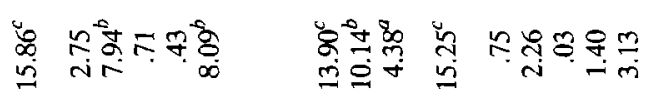

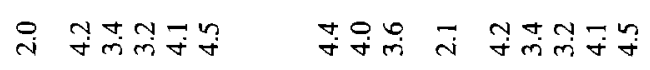

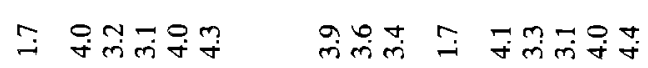

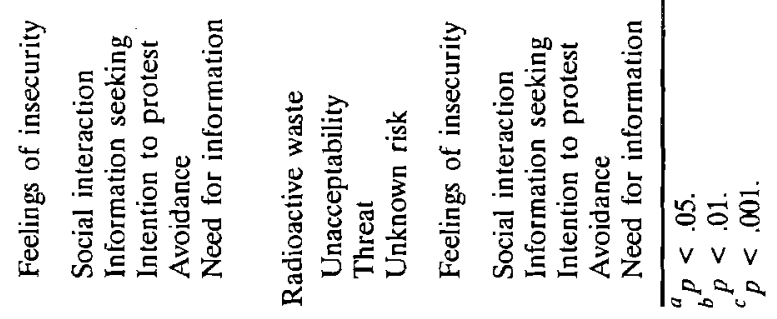


$135)=1.26, \mathrm{~ns}]$. Women with a lower level of education assess this risk object as more unknown than men with a lower level of education $[F(1$, $135)=3.87, p=.05]$. No significant differences between men and women with average $[F(1,205)=3.31, p<.10]$ or higher levels of education $[F(1$, $113)=1.36, \mathrm{~ns}]$ are found with respect to the familiarity of the risk object of chemical plant.

There is also a significant interaction effect between gender and level of education for feelings of insecurity regarding the risk object of polluted estate $[F(2,429)=4.38, p<.05]$. Secondary analyses showed that women with a lower level of education $[F(1,126)=13.72, p<.001]$ and with a higher level of education $[F(1,111)=5.12, p<.05]$ report more feelings of insecurity than men with these levels of education. No difference in feelings of insecurity evoked by the risk object of polluted estate was found for men and women with an average level of education $[F(1,193)=.08$, $\mathrm{ns}$.

\section{CONCLUSIONS}

In this study we established to what extent demographic characteristics such as gender and educational level correlate with reactions to three environmental hazards, namely living in an estate in which soil pollution has been established (the risk object of polluted estate), living in the vicinity of a planned storage facility for radioactive waste (the risk object of radioactive waste), and living in the neighborhood of a chemical plant (the risk object of chemical plant). Respondents had to imagine living in the vicinity of these risk objects. The reactions to environmental hazards were distinguished into three categories, namely the assessment of the hazard, the feelings of insecurity due to the hazard, and the ways of coping with the hazard. In general, differences were found in the way people reacted to these three hazards, which leads to the conclusion that this manipulation has been successful. We established that men and women differed with respect to the assessed unacceptability of the risk objects of polluted estate and radioactive waste, and for all three risk objects with respect to the threat posed by the hazard; women judged the hazards to be more unacceptable and more threatening. In general, our results do not appear to support the assumption of Weenig (1983), that differences between men and women can be attributed to the fact that women are less familiar with technology. Only for the risk object of radioactive waste did significant differences exist between men and women with respect to the assessment of the familiarity of the risk; women judged this hazard to be less known. This implies that men and women did not differ in the assessment 
for two of the three risk objects. Moreover, we found that for all three environmental hazards women reported more feelings of insecurity than men. This result agrees with earlier studies (Vlek \& Stallen, 1979; Stallen \& Tomas, 1988; Pilisuk \& Acredolo, 1988). The assumption of Stallen and Tomas (1988) that the differences in the feelings of insecurity between men and women exist because women are less open to the economic advantages of hazards of this type does not agree with the results of the present study. For the risk objects of chemical plant and radioactive waste, this assumption could be valid, but certainly not in the case of living in an estate with soil pollution, because here the advantages are far from obvious. Differences in feelings of insecurity between men and women have also been found with respect to other risk objects, such as fear of cancer (Seydel, 1989 ) and the fear of criminal victimization (Garofalo, 1979; Van den Bogaard, 1990). Hence, a more general role differentiation explanation must be sought, which emphasizes the cultural process based on socialization in which females learn to take a more dependent role and will be less inhibited to show their feelings of anxiety, and so will be more worried about technological and industrial developments. On the basis of their independent role, men are not allowed to show their weaknesses, and are taught to deny or minimize fear and feelings of anxiety.

For two of the three risk objects differences in feelings of insecurity were found between people with various educational levels. This is not remarkable as such differences could be expected on the basis of earlier research, both relating to technology (Pilisuk \& Acredolo, 1988) and health (Gutteling, Wiegman, \& Boek, 1986; Seydel, 1989). Furthermore, the educational groups differ with respect to the specific aspects of the judgment of the risk objects. The chemical plant and the polluted estate were judged to be less known by higher educated people than people with lower educational levels. An explanation for this could be that, in general, higher educated people are more familiar with certain technological developments, on the base of their formal education, but hazards such as living in a polluted estate and in the vicinity of a chemical complex are not covered by their education and are rated as more unknown. The risk object of polluted estate was also judged to be more threatening by the higher educated group. This could be explained by the fact that the latter group includes higher incomes, and also more house owners (CBS, 1987), who are more afraid of depreciation of their property. The risk object of radioactive waste was judged by the higher educated respondents to be less unacceptable than by the groups with lower levels of education. This agrees with the finding of Midden (1986) that the highly educated have a more positive attitude to the use of nuclear power. These results also agree with the hypothesis of Pilisuk and Acredolo (1986) that people who have less to 
gain from technological developments (i.e., the lower educated persons) have a less positive attitude.

\section{REFERENCES}

Baas, L. W., De Boer, J., Geerlings, H., Hoefnagel, B., \& Van der Wouden, J. C. (1985). Psychosocial aspects of soil pollution. The Hague: Government Printing Office.

Baum, A., Gatchel, R. J., \& Shaeffer, M. A. (1983). Emotional, behavioral and physiological effects of chronic stress at Three Mile Island. Journal of Consulting and Clinical Psychology, 51, 565-572.

CBS. (1985). Statistical Pocketbook, 1985. The Hague: Government Printing Otfice.

CBS. (1987). Research to housing needs 1985/1986. The Hague: Government Printing Office.

Diederen, J. (1989). More or less unequal. Nijmegen, the Netherlands: dissertation.

Ester, P., Mindell, V., Van der Linden, J., \& Van der Pligt, J. (1983). The influence of living near a nuclear power plant on beliefs ahout nuclear energy. Zeitschrift für Umweltpolitik, 4, 349-362.

Fischer, W. G., Morgan, M. G., Fischhoff, B. N., Nair, I., \& Lave, L. B. (1991). What risks are people concerned about? Risk Analysis, 11, 303-314.

Garofalo, J. (1979). Victimization and the fear of crime. Joumal of Research in Crime and Delinquency, 16, 80-97.

Gutteling, J. M., Seydel, E. R., \& Wiegman, O. (1986). Perceptions of cancer. Joumal of Psychosocial Oncology, 4, 77-92.

Gutteling, J. M., Wiegman, O., \& Boer, H. (1990). Living distance and reactions to the direct confrontation with an industrial hazard. Nederlands Tijdschrift voor de Psychologie, 45, 17-24.

Midden, C. J. H. (1986). Individual and largescale technology: A comparative attitude study to the production of electricity with coal and uranium. Leiden: Dissertation.

Pilisuk, M., \& Acredolo, C. (1988). Fear of technological hazards: One concern or many? Social Behaviour, 3, 17-24.

Renn, O. (1981). Man, technology and risk: $A$ study on intuitive risk assessment and attitudes towards nuclear energy. Jülich: Kernforschungsanlage Jülich $\mathrm{GmbH}$, Programmagruppe Kernenergie und Umwelt.

Seydel, E. R. (1989). Cancer and the general public: Experiments with public education about cancer: Enschede: Dissertation

Slovic, P. (1987). Perception of risk. Science, 236, 280-285.

Stallen, P. J. M., \& Tomas, A. (1988). Public concern about industrial hazards. Risk Analysis, $8,237-245$.

Van den Bogaard, J. (1990). Police services and coping with burglary: Final report of a policy related research project in the eastern part of Overijssel. Enschede: Department of Psychology.

Van der Ploeg, H. M., Defares, P. B., \& Spielberger, C. D. (1980). Manual of the Self-Judgment Questionnaire. Lisse: Swets and Zeitlinger.

Vlek C. A. J., \& Stallen, P. J. M. (1979). Personal judgment of risks: On risks, benefits and acceptability of individual, societal and industrial activities. Groningen: Institute for Experimental Psychology.

Weenig, M. (1983). The perception of risks of large scale technologies: $A$ study of gender differences in risk perception with respect to nuclear energy. Leiden: Department of Social and Organizational Psychology.

Wiegman, O., Gutteling, J. M., \& Boer, H. (1990). Public reactions to the confrontation with an industrial hazard. In: H. B. F. Gow and H. Otway (eds.): Communicating with the public about major accident hazards. London: Elsevier Applied Science Publishers, pp. $429-439$. 
Wiegman, O., Gutteling, J. M., \& Boer, H. (1991). Verification of information through direct experiences with an industrial hazard. Basic and Applied Social Psychology, 12(3), 325-339. Wiegman, O., Komilis, E., Cadet, B., Boer, H., \& Gutteling, J. M. (1992). The development of reactions of the public to warning and emergency situations in France, Greece and the Netherlands. The Journal of Social Psychology, 132, 101-116. 